
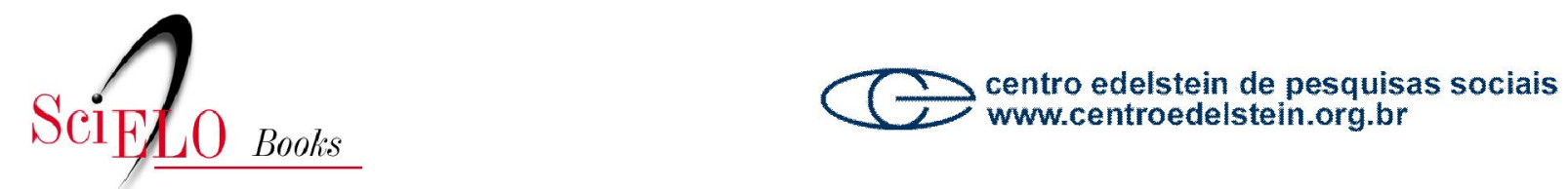

\title{
A empresa e seus fornecedores de leite
}

\author{
Antoinette Fredericq
}

CORADINI, OL., and FREDERICQ, A. Agricultura, cooperativas e multinacionais [online]. Rio de Janeiro: Centro Edelstein de Pesquisas Sociais, 2009. pp. 126-152. A empresa e seus fornecedores de

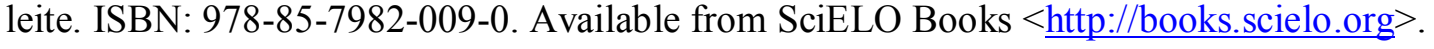

\section{(1) (1)(2)}

All the contents of this chapter, except where otherwise noted, is licensed under a Creative Commons Attribution-Non Commercial-ShareAlike 3.0 Unported.

Todo o conteúdo deste capítulo, exceto quando houver ressalva, é publicado sob a licença Creative Commons Atribuição Uso Não Comercial - Partilha nos Mesmos Termos 3.0 Não adaptada.

Todo el contenido de este capítulo, excepto donde se indique lo contrario, está bajo licencia de la licencia Creative Commons Reconocimento-NoComercial-CompartirIgual 3.0 Unported. 


\section{A empresa e seus fornecedores de leite}

A Nestlé é uma das maiores empresas alimentícias brasileiras, em termos do número de produtores rurais a ela subordinados: no Brasil, mais de 40 mil produtores dependem de suas compras, somente no caso do leite. A empresa já foi citada por Kautsky, no fim do século passado, como exemplo típico da dominação do capital sobre formas de produção camponesa. ${ }^{1}$ Ver-se-á, aqui, quais são as razões pelas quais uma empresa desse tipo escolheu não se encarregar ela mesma da produção de sua principal matéria-prima, e como se adaptou às condições do campo brasileiro.

\subsection{Algumas reflexões sobre a persistência da produção familiar no} campo

A tendência à concentração da propriedade foi vista, durante muito tempo, como única saída possível para a agricultura. O próprio Marx achava que as pequenas unidades de produção tradicionais não seriam capazes de concorrer, a longo prazo, com grandes estabelecimentos capitalistas, transpondo, assim, para a agricultura, o esquema da concentração industrial do século XIX.

Um século mais tarde, no entanto, a pequena exploração familiar ainda não foi eliminada, nem nos países de industrialização mais antiga, nem em sociedades periféricas: continua existindo, apesar da modernização do campo e da possível concorrência de estabelecimentos capitalistas com alto grau de concentração e uso de trabalho assalariado.

Em artigo recente, Servolin resumiu as vantagens que favorecem a pequena exploração familiar e explicam sua permanência, impedindo sua transformação em empresas capitalistas. Ele destacou três razões para explicar esse fenômeno.

A primeira é relacionada à especificidade do processo de trabalho agrícola: suas características não permitem uma divisão do trabalho muito desenvolvida nos vários estágios da produção. Estes não podem ser

\footnotetext{
${ }^{1}$ Kaustsky, 1977, v. II, p.144
}

realizados de maneira conjunta, porque são submetidos ao próprio ritmo biológico da natureza. A parte principal do processo de produção é desenvolvida pelas células vegetais ou animais, e escapa, pois, à decomposição analítica que permitiu a passagem, no processo de produção industrial, para a manufatura e, depois, para a indústria capitalista.

Em vista do atual estágio de desenvolvimento tecnológico referente à produção agrícola, a divisão do trabalho não é compensadora e ganhos de escala representam poucas vantagens (com algumas exceções, tal como na produção avícola). A pequena exploração familiar pode, portanto, assumir a produção de vários produtos, sem ser desqualificada pela concorrência capitalista.

O segundo ponto levantado por Servolin retoma uma observação feita anteriormente por Marx: uma unidade de produção capitalista somente é rentável se alcançar a taxa de lucro médio vigente no resto da economia. No caso de uma pequena exploração familiar, ao contrário, o objetivo não é a valorização do capital investido, nem a obtenção de lucro, mas a reprodução de seus meios de produção e a subsistência da comunidade familiar. $\mathrm{O}$ produtor familiar pode renunciar à renda da terra, ao lucro e à amortização de seu capital, pode até renunciar a um salário correspondente ao pago pela indústria, e se satisfazer unicamente com a possibilidade de sua reprodução simples.

Na agricultura, portanto, a empresa capitalista parece não apresentar vantagens significativas no plano técnico e ser mais vulnerável, no plano econômico, que a unidade familiar tradicional.

O terceiro argumento levantado por Servolin para explicar a permanência dessa forma de produção pré-capitalista é a instituição da propriedade privada da terra; a compra de terra significa a mobilização de um capital totalmente improdutivo, o que pouco interessa a empresas capitalistas que procuram uma rápida circulação de dinheiro. Ou, como diz Alberto Passos Guimarães, “o investimento dedicado à compra da terra (...), ou ao pagamento da renda da terra arrendada, desvia do produtor capitais que, se aplicados na produção, não só reduziriam seus custos como possibilitariam sua expansão. Desse modo, o investimento desviado da produção atua como um limite à acumulação de capitais" (Guimarães, 1979, p. 151). 
Isso significa que, ao lado do desenvolvimento de uma agricultura tipicamente capitalista, a pequena produção tradicional continua reproduzindo-se. As duas formas de produção passaram a coexistir, especializando-se em produtos específicos, em formações sociais ou em momentos históricos diferentes.

2.2 Apropriação do sobretrabalho camponês pelo capital e estratégias das grandes empresas alimentícias

Não é durante o processo de produção propriamente dito que o capital se apropria do sobretrabalho camponês: é no processo de circulação dos produtos agrícolas (Faure, 1977). Enquanto estamos na esfera da produção agrícola tradicional, não distinguimos capitalista, proprietário fundiário ou proletário; há somente um produtor. Mas, quando esse produtor vende suas mercadorias a um preço mais baixo que seu valor o que só garante a reprodução de sua força de trabalho - está transferindo um excedente para o capital comercial ou industrial com que trata. Isso explica por que o modo de produção dominante capitalista integrou e subordinou, dessa maneira, elementos pré-capitalistas, apesar de que estes últimos podem significar, em outros aspectos, limites para a acumulação de capital, no conjunto da economia.

A indústria de transformação, no entanto, não pode ser considerada como um setor autônomo, beneficiário exclusivo da captação do excedente agrícola. Num sistema de economia concorrencial, o alcance de um lucro particularmente alto atrairia novas empresas para esse setor, o que automaticamente faria declinar a taxa de lucro.

O excedente agrícola somente poderá ser realizado pela indústria de transformação se esta possuir um controle monopólico de seu mercado, caso em que o sobrelucro poderá ser muito importante. Mas, nesse caso, ainda deverá resistir às pressões das classes dominantes, em sua luta pelo controle dos preços alimentícios. Este permite uma reprodução mais barata da força de trabalho e uma transferência do excedente agrícola para o resto da economia (Hairy, 1973), o que beneficia, em última instância, o capital em seu conjunto.
Que caminhos restaram ao grande capital concentrado para obter um sobrelucro na esfera alimentícia? Depois de seus esforços para conseguir o controle monopólico dos mercados de alimentos industrializados de grande difusão, começou a expandir-se em áreas novas, menos controladas pelo poder público. Passou a produzir alimentos sofisticados, de forte valor agregado, destinados prioritariamente às camadas de maior poder_ aquisitivo. Essa introdução e difusão crescente de alimentos "rentáveis" no mercado, além das mencionadas mudanças no padrão nutricional popular, leva, também, a um encarecimento gradual da alimentação no Brasil. Isso sem contar com os altos custos de marketing, publicidade, embrulhos sofisticados e atraentes etc., aos quais as grandes empresas alimentícias recorrem sistematicamente.

\subsection{Capital transnacional e produção agropecuária}

Os aspectos que garantiram a sobrevivência da pequena exploração familiar dentro de formações sociais predominantemente capitalistas são os mesmos que tornaram a produção direta pouco atraente para o grande capital transnacional: a especificidade do processo de trabalho agrícola, a concorrência com explorações familiares que não dependem do alcance de lucros e a necessária imobilização de um capital destinado à compra da terra. Todos esses aspectos restringiram a participação direta do capital transnacional na agricultura.

O setor de produção de leite, por exemplo, é particularmente adaptado a um esquema produtivo de pequenas unidades. A constituição de grandes estabelecimentos cooperativos ou estatais, na URSS e nos países de sua influência, levou-os a fracassos, tanto do ponto de vista técnico quanto financeiro: o tamanho "ideal" de uma exploração leiteira corresponde ao número máximo de animais de que um produtor pode cuidar (com eventual ajuda, para certos trabalhos periódicos). Ultrapassando esse limite, funcionará como simples justaposição de processos de trabalho individuais. Estudos específicos demonstraram que, nesse caso, a produtividade por animal não apresenta melhorias ou até mesmo diminui, o que não justifica investimentos suplementares para conseguir ganhos de escala (Servolin, 1979). 
O fato de não se dedicar à produção agropecuária direta permite também escapar aos riscos dessa atividade tão aleatória. O leite, por exemplo, apresenta uma produção muito irregular (excesso na época de chuvas, falta na entressafra). As empresas compradoras, motivadas por causas financeiras, podem decidir uma redução de seus estoques de laticínios durante a época de safra, e recusar-se a comprar leite de seus fornecedores: nesse caso, são estes que assumem o risco de sua produção e têm de arcar com os problemas enfrentados pelas empresas transformadoras no mercado.

Uma outra razão para não entrar na produção agropecuária propriamente dita já foi citada anteriormente: a compra de matéria-prima "barata", quando reforçada por uma posição de monopólio, pode garantir às empresas transformadoras a realização do excedente proveniente da agricultura. $^{2}$

As vantagens enumeradas, no entanto, não são estáticas, nem absolutas: em certas circunstâncias, a produção direta apresenta atrativos bastante fortes para compensar os problemas que provoca. No Brasil, por exemplo, incentivos fiscais e preocupações especulativas atraíram, para a agricultura, corporações transnacionais que nunca se tinham dedicado a esse tipo de atividade. De outro lado, os progressos da tecnologia agrícola podem mudar o quadro atual, que favorece as pequenas explorações.

Atualmente, é uma constante na política da Nestlé, por exemplo, nunca entrar na produção direta de leite (nem de cacau, café, açúcar ou outras matérias-primas de que precisa).

Para que pudesse funcionar economicamente, no entanto, contando com um abastecimento regular de matéria-prima de boa qualidade, foi preciso desenvolver mecanismos próprios de controle da produção, induzindo os produtores a utilizarem as técnicas que mais beneficiam a empresa. Isso implica um delicado jogo de equilíbrio entre modernização e conservação de técnicas produtivas tradicionais.

${ }^{2}$ Ao lado desses fatores, que, sem dúvida, são essenciais, temos de lembrar também o elemento político: a posição de uma empresa estrangeira que não possui rebanho, plantações, nem terras, mas se encarrega unicamente da transformação de produtos agropecuários, escapa mais facilmente às ameaças de eventuais correntes nacionalistas, dirigidas contra empreendimentos de capital transnacional no setor de produtos alimentícios básicos.
De um lado, é preciso aumentar a produção de leite, para aproveitar a economia de escala da fábrica e ampliar o lucro da empresa. De outro lado, esse aumento da produção não pode depender demais da aquisição, pelo produtor, de insumos modernos, que elevarão seus custos e, consequentemente, o preço de venda de sua matéria-prima: o volume disponível deve crescer, mas seu preço deve ser o mais baixo possível!

Aqui ressalta a importância de um serviço de assistência técnica, que faz a ligação entre a empresa e seus produtores, induzindo estes últimos a produzirem mais leite, sem aumentar demais seus custos.

\subsection{Implantação e consolidação das fábricas de leite Nestlé}

A localização dessas fábricas de leite no Brasil corresponde à evolução constatada em outros países da América Latina, onde o grupo suíço está implantado há várias décadas ${ }^{3}$ : sua instalação começou em locais relativamente próximos aos maiores centros urbanos, e foi-se afastando cada vez mais para regiões menos industrializadas.

No Brasil, suas primeiras fábricas de laticínios foram implantadas na proximidade das cidades de São Paulo, Rio de Janeiro e, mais tarde, Belo Horizonte. As fábricas da década de 1960 já se encontram mais afastadas desses centros, no interior mais longínquo dos Estados de São Paulo, Rio e Minas Gerais. Durante a década de 1970, foram instaladas três fábricas de leite em pó: uma no Triângulo Mineiro, uma no Norte e uma no Nordeste do país.

Este último deslocamento não foi provocado única e exclusivamente pelo regime de incentivos fiscais que atrai investimentos industriais para essas regiões. Parece ser um meio da Nestlé evitar enfrentar a concorrência direta com outras empresas compradoras, e escapar, assim, à acusação de que seria responsável pela escassez do leite fluido no mercado. De outro lado, pode ser mais fácil, para a empresa, implantar fábricas em novas regiões do que lutar contra os fatores que contribuem para a descapitalização das unidades produtivas localizadas nas bacias leiteiras

${ }^{3}$ Nestlé, 1975 
tradicionais, tal como, por exemplo, o crescimento acelerado do preço da terra.

A empresa está sempre se deslocando, pois, para novas regiões (principalmente regiões de gado de corte), onde se instala como única compradora e começa a organizar novas bacias leiteiras. No Brasil, a localização dessas novas fábricas corresponde a mais uma vantagem: nas regiões escolhidas, a época de chuvas acontece exatamente na entressafra da bacia leiteira tradicional. Isso permitirá a produção máxima de leite em pó durante a época em que há maior falta desse produto no mercado.

Implantar uma fábrica de leite em pó numa região com pouca produção leiteira não é, porém, uma tarefa ao alcance de qualquer empresa. A Nestlé tem uma longa prática disso, e começa os contatos com seus futuros fornecedores até quatro anos antes de começar a construção da fábrica. Os técnicos de seu serviço de assistência aos produtores visitam as fazendas, convencem os fazendeiros a comercializarem o leite, que eventualmente já é subproduto de sua atividade, e lhes dão as informações necessárias para organizar (ou aperfeiçoar) sua produção. Assim, o fornecimento leiteiro já está assegurado no dia em que a nova fábrica começa a funcionar.

Segundo a própria empresa, o sucesso da implantação de suas fábricas depende de dois fatores básicos: a existência de uma eficiente equipe de assistência técnica e a organização de um bom sistema de recolhimento de leite. Esses dois fatores são essenciais ao desenvolvimento da produção leiteira das regiões escolhidas, mas constituem, também, as chaves da relação de subordinação criada entre a Nestlé e seus fornecedores.

\subsection{Assistência Nestlé aos produtores de leite}

O serviço de assistência técnica da empresa, a ANPL (Assistência Nestlé aos Produtores de Leite), foi criado em 1952 e contava, em 1976, com 107 técnicos responsáveis pela ligação entre a Nestlé e seus mais de 20 mil produtores não-associados a cooperativas. Segundo a empresa, esse serviço foi criado para resolver o problema da irregularidade do fornecimento e aumentar a produtividade, racionalizando a produção de seus fornecedores.

A ANPL apoia suas atividades técnicas em alguns pontos básicos. O primeiro é a necessidade de uma alimentação adequada para o gado, produzida, na medida do possível, na própria fazenda, para permitir uma economia de razões concentradas: a equipe técnica ajuda na formação de pastagens e de capineiras, e incentiva muito a introdução de silagem nas fazendas. Outra atividade essencial é sua ajuda na profilaxia do rebanho e na higiene da produção: seus técnicos ensinam, por exemplo, como aplicar vacinas e pulverizar o gado contra ectoparasitas, facilitando a aquisição dos remédios e equipamentos necessários.

A empresa participa ainda, ativamente, da melhoria progressiva do rebanho: mantém granjas experimentais, onde cria reprodutores de linhagem, para serem vendidos aos fornecedores pelo preço de custo, em prestações mensais retidas do pagamento do leite fornecido. Essa assistência financeira não se restringe à venda de bezerros pela empresa, mas atinge também a aquisição de insumos, a construção de silos ou estábulos etc. Raramente se trata de montantes muito elevados, mas, mesmo para quantias reduzidas e prazos de alguns meses, cria laços de forte dependência entre os produtores e a empresa.

Esse trabalho de assistência é baseado em pesquisas de campo regulares, que fazem um levantamento das técnicas produtivas utilizadas pelos produtores e da estratégia a ser seguida pela ANPL. No quadro 6, temos um apanhado das atividades deste órgão entre os produtores, de 1972 a 1976.

Fica claro, no quadro a seguir, o grande incentivo fornecido pela ANPL à formação de capineiras e de silos nas propriedades dos seus fornecedores. A tonelagem dos novos silos construídos com a ajuda da Nestlé se elevou a uma taxa média anual de $71 \%{ }^{4}$ Por outro lado, os financiamentos de equipamentos e máquinas parecem estar se tornando cada vez mais secundários.

\footnotetext{
${ }^{4}$ Comparando o número de silos com o das fazendas onde estão localizados, notamos que se trata, principalmente, de construções em fazendas que já possuem silos, e que são, portanto, estabelecimentos maiores.
} 
A empresa incentiva a compra de remédios e sementes pelos seus fornecedores de duas maneiras: ou comprando esses insumos em grande quantidade, para revendê-los, ou, então, facilitando sua aquisição direta, através de financiamentos. A ANPL também busca divulgar novas técnicas de seu interesse, através de reuniões de produtores de leite e publicação de folhetos e histórias em quadrinhos, redigidos em linguagem simples. Colabora, também, com organismos oficiais de assistência técnica, e mantém convênios com Escolas de Veterinária e com o Instituto de Zootecnia, da Secretaria de Agricultura de São Paulo.

\section{Quadro 6}

Atividades do serviço de assistência técnica da Nestlé

entre os produtores de leite (1972-76)

\begin{tabular}{lrrrr}
\hline & $1972-73$ & $1973-74$ & $1974-75$ & $1975-76$ \\
\hline Técnicos & 65 & 84 & 89 & 107 \\
Visitas de assistência técnica & 17.138 & 19.397 & 24.649 & 27.687 \\
Reuniões promovidas & 408 & 496 & 624 & 692 \\
Participantes & 4.855 & 6.514 & 7.859 & 7.936 \\
Construção de silos* & 513 & 918 & 980 & 1.808 \\
Tonelagem dos silos & 20.353 & 34.717 & 42.934 & 93.944 \\
Fazendas com silos & 2.612 & 3.200 & 3.236 & 4.004 \\
\% do total de propriedades & 15,9 & 18,3 & 16,4 & 20,4 \\
Formação dẹ capineiras (ha)* & 4.554 & 6.653 & 7.136 & 9.404 \\
Construção de estábulos* & 283 & 387 & 387 & 466 \\
Represas construídas* & 196 & 210 & 522 & 592 \\
Reprodutores bovinos & & & & \\
$\quad$ fornecidos* & 318 & 309 & 368 & 326 \\
Equipamentos e máquinas* & 446 & 496 & 442 & 365 \\
Arame farpado fornecido & & & & \\
(metros)* & 1.699 .300 & 1.358 .814 & 916.550 & 2.499 .250 \\
\hline
\end{tabular}

Fonte: Folheto Nestlé.

* Através de adiantamento em dinheiro pela ANPL.

As informações anteriores podem ser lidas em qualquer artigo de propaganda da Nestlé. A imagem que quer difundir sobre o trabalho de seus serviços de assistência é essencialmente técnica, e privilegia sempre sua colaboração para o aumento da produção. A função da ANPL, no entanto, é bem mais vasta que isso, e abrange mecanismos que a empresa desenvolveu para tentar subordinar os produtores.

O que interessa saber, no caso, é como funciona concretamente esse sistema de assistência técnica. Está organizado em torno de algumas fazendas prioritárias, que servem de foco de irradiação das técnicas a serem implantadas. ${ }^{5}$ A escolha das fazendas prioritárias é feita em função de uma pesquisa prévia sobre quem são as lideranças da região. Essas lideranças são constituídas, na maioria dos casos, de grandes produtores, mas podem, também, ser formadas de produtores médios ou pequenos que irão crescendo. São escolhidas por sua influência entre a população local é receberão o privilégio de uma assistência bem mais intensiva e de uma prioridade absoluta no trabalho dos técnicos (enquanto, muitas vezes, pequenos produtores isolados e de produção insignificante nunca viram os técnicos da empresa, em 27 anos de existência da ANPL).

O favorecimento das lideranças entre seus produtores de leite é importante para a difusão das novas técnicas de produção: os fazendeiros comumente são mais influenciáveis pelo que acaba de ser implantado na fazenda do "vizinho rico e bem-sucedido", do que pelos conselhos de técnicos que não arcam com os riscos da produção. De outro lado, é importante que a empresa possa contar com a simpatia dessas lideranças, para não ser ameaçada por elas na hora em que surgem novos concorrentes na região, em busca de leite cru. Como raramente um produtor muda de comprador sozinho (ele faz parte de uma corrente ou "linha de leite"), deverá convencer vários produtores da linha a mudar com ele, para que o transporte do leite até a nova usina seja mais "rentável". É evidente que, nesse esquema, interessa muito à Nestlé que as lideranças tenham estreitos laços de dependência em relação a ela, laços criados pelo medo de perder os benefícios de uma assistência técnica prioritária.

Com essa política de favorecimento de alguns fornecedores mais dinâmicos, o grupo transnacional participa, ativamente, do processo capitalista de diferenciação dos produtores: um número restrito, escolhido, pela empresa, por suas características pessoais de liderança e por suas possibilidades de capitalização, é incentivado prioritariamente a aumentar

\footnotetext{
${ }^{5}$ Assistência Nestlé aos Produtores de Leite, 1968.
} 
sua produção e sua renda, enquanto a grande maioria dos produtores é relegada a um segundo plano e recebe somente uma assistência episódica. ${ }^{6}$

A Nestlé, graças a seu serviço de ajuda técnica e à sua constante demanda de leite, que dá ao produtor a certeza de sempre conseguir vender seu produto, incentivou um aumento espetacular da produção nas regiões em que se instalou. Em Araras (SP), por exemplo, onde foi implantada sua primeira fábrica no país, de uma pequena produção inicial de 2 mil toneladas de leite fresco, em 1921, passou-se a industrializar $700 \mathrm{mil}$ toneladas, em 1975. Não se pode afirmar que tal crescimento se deva exclusivamente à presença da Nestlé na região, mas seu papel foi, sem dúvida, importante.

É inegável que o grupo suíço conseguiu aumentar a produção das regiões em que atua, mas já vimos, também, que esse crescimento nem sempre corresponde a um aumento proporcional da renda dos produtores. De outro lado, em certos momentos, a empresa está mais interessada em diminuir seu recebimento que em aumentá-lo. O que faz, nesse caso? Manda seus técnicos para o campo, aconselhando os produtores a diminuírem a administração de ração, porque suas vacas precisam descansar, e provoca, assim, um decréscimo da produção de leite. Ou, como disse um produtor ligado à empresa: "O papel do técnico é convencer o fazendeiro de que o que é vantagem para a companhia também é vantagem para ele".

Para conseguir influenciar os fornecedores dessa maneira, é necessário que estes sintam certa confiança no técnico da empresa. Isso explica a importância dada pela Nestlé (e realçaria em suas publicações) ao "bate-papo" que o técnico terá, com os produtores, sobre o tempo, a colheita etc. Esse "bate-papo" informal é, ainda, essencial para informar a empresa sobre as dificuldades ou os projetos de seus fornecedores.

A ANPL desempenha um papel importante na relação entre a empresa e seus fornecedores, mas esse papel também não pode ser superestimado: os produtores não escolhem vender seu leite para a Nestlé por causa de seu serviço de assistência técnica, mas, sim, porque é "boa

\footnotetext{
${ }^{6}$ Não podemos, no entanto, deixar de lado, aqui, outro aspecto dessa assistência técnica: a que está sendo levada aos produtores, através de reuniões e publicações especializadas, e que conta com um público mais amplo.
}

compradora" (ver mais para a frente). Além disso, tem-se notado, durante os últimos anos, que a empresa está desativando a ANPL em suas regiões de implantação antiga: ela não parece mais preencher uma função essencial, quando o fornecimento de leite é considerado satisfatório.

\subsection{Linhas de leite}

O segundo fator importante para o desenvolvimento da produção leiteira, na região de implantação de uma nova fábrica, é a organização de uma eficiente rede de recolhimento do leite. Quem organiza as linhas de leite e decide a respeito do itinerário e do horário é a empresa transformadora. Mas quem paga o transporte, da fazenda até o posto de recebimento e do posto de recebimento até a fábrica, são os produtores. Eles pagam à empresa um preço fixo de alguns centavos por litro de leite transportado, e esta paga, por sua vez, ao carreteiro, em função da quilometragem rodada. Essas duas quantias podem não ser iguais, sendo que, nesse caso, quem normalmente leva vantagem é a empresa.

Não deve ser essa vantagem financeira, no entanto, que motiva a Nestlé a controlar, a todo custo, a rede de transporte, mesmo em bacias leiteiras organizadas há décadas: é que isso lhe permite pressionar melhor os produtores, quando necessário. Se um grande produtor da linha, por exemplo, decide vender seu leite, de agora em diante, para um concorrente que lhe oferece um preço mais alto, a empresa pode ameaçar os fornecedores restantes de fortes acréscimos nos custos operacionais, ou de, simplesmente, abandonar a linha, esperando, assim, que eles consigam evitar a desistência. Em época de excesso de leite, ao contrário, e quando segue uma política de diminuir seu recebimento diário, pode simplesmente fechar uma linha, declarando-a "menos rentável".

\footnotetext{
${ }^{7} \mathrm{Na}$ época da pesquisa de campo realizada na cidade mineira de Três Corações, estava acontecendo o seguinte conflito: os produtores de uma linha haviam descoberto que seu carreteiro recebia somente $60 \%$ da quantia paga mensalmente por eles ao grupo suíço para tal fim. Como ele se queixasse de receber um salário insuficiente e a Nestlé se recusasse a aumentá-lo, o grupo de produtores decidiu contratá-lo de maneira direta, sem utilizar mais a empresa como intermediária. Esta reagiu, exercendo fortes pressões sobre os produtores, para que desistissem do plano, e acabou autorizando o aumento salarial, para que ele não se realizasse. 
Apesar de os fazendeiros pagarem a organização do transporte do leite, seu poder sobre ela é bastante reduzido.

Com o tempo, cada empresa compradora de leite estabeleceu, assim, seu "território", delimitado por suas linhas fixas de fornecimento. E esse território normalmente é respeitado por suas concorrentes: é somente em situações excepcionais que estas tentam expandir-se à custa de uma empresa de porte parecido, quebrando, desse modo, o acordo implícito vigente. Existem, no entanto, alguns territórios sobrepostos nas bacias leiteiras tradicionais, onde a luta pelo leite toma proporções mais sérias.

Já foram citadas, aqui, algumas técnicas de controle que podem diminuir a "independência" dos produtores em relação à Nestlé. Essas técnicas (assistência técnica e creditícia, controle de transporte) podem ser utilizadas pela empresa para pressionar seus produtores, nas ocasiões em que julga necessário. Não constituem, porém, mecanismos que controlem totalmente a produção leiteira regional, como seria no caso de a empresa assumir, ela própria, a produção, ou de desenvolver mecanismos de integração vertical.

\subsection{A Nestlé, os produtores e suas cooperativas}

As cooperativas de produtores de leite formam uma boa ilustração de alguns dos caminhos seguidos pelo movimento cooperativista dentre as possibilidades do atual modelo de desenvolvimento brasileiro.

As primeiras cooperativas leiteiras surgiram durante a década de 1930 no Estado de São Paulo, pela iniciativa de grandes e médios produtores. Eles tentaram organizar-se, a fim de responder à crescente demanda de alimentos para o mercado urbano. Como o leite é um produto altamente perecível, os produtores se encontravam numa situação de dependência muito grande em relação aos compradores, e sentiram, desde cedo, a necessidade de se unirem para comercializar seu produto, primeiro em cooperativas regionais e depois em cooperativas centrais.

Essa dependência dos produtores de leite é particularmente importante (eles não têm possibilidade de estocar seu produto para pressionar o setor de comercialização) e explica a rápida expansão do movimento cooperativista dentro do setor. Atualmente, cerca de 50\% dos produtores de leite brasileiros são filiados a uma cooperativa.

No que diz respeito a seu funcionamento e à sua autonomia de decisão, as cooperativas leiteiras regionais apresentam características bastante diversas: algumas entre elas funcionam de maneira independente, outras são filiadas a cooperativas centrais, outras ainda se ligaram a empresas de transformação de capital privado, entregando-lhes toda a produção de seus cooperados.

Os serviços prestados pelas cooperativas regionais aos produtores também não são uniformes, e dependem da própria cooperativa. Ao lado de um posto de recebimento de leite, esta poderá ter um armazém de abastecimento de insumos, um departamento de assistência técnica, um posto de inseminação artificial etc. Quanto às cooperativas centrais, elas também têm uma orientação própria na sua política leiteira. A Cooperativa Central do Estado de São Paulo, por exemplo, incentiva a produção de leite B, a Cooperativa Central do Paraná ressalta a necessidade de melhoria da qualidade do leite $\mathrm{C}$, enquanto a Cooperativa Central do Rio de Janeiro está especialmente preocupada com sua concentração e crescimento.

A evolução dessas cooperativas centrais é caracterizada por sua tentativa de melhorar, cada vez mais, sua capacidade competitiva, num comportamento que corresponde ao de qualquer empresa capitalista. Para sobreviver e crescer tiveram de se adaptar à estrutura econômica vigente como entidades empresariais: disputando o mercado com poderosas empresas estrangeiras, as cooperativas centrais começaram a produzir os mesmos produtos sofisticados que precisam de tecnologia importada e se lançaram em grandes projetos de propaganda e marketing. Nesse sentido, estão seguindo a tendência geral notada no setor leiteiro brasileiro como um todo, dedicando uma parte cada vez maior da matéria-prima recebida à produção de derivados de luxo. A participação do leite $\mathrm{C}$ na produção das cooperativas centrais filiadas à CBCL, por exemplo, caiu em um ano (de 1975 para 1976), de $64 \%$ para $57 \%$.

As cooperativas leiteiras centrais se beneficiam do mesmo fenômeno de captação de excedentes da produção que as outras empresas transformadoras, mas aqui a captação se faz em dois níveis: uma primeira 
vez, a nível dos produtores, e uma segunda vez, a nível das cooperativas regionais.

$\mathrm{Na}$ medida em que as cooperativas regionais se encarregam principalmente da entrega do leite in natura e em que as centrais (que dispõem de maior capacidade produtiva e financeira) cuidam da industrialização, somente estas últimas conseguem certa rentabilidade. É um modo que as centrais encontraram para reforçar o poder financeiro de que precisam, em sua concorrência com empresas de capital privado nacional e transnacional, transferindo os ônus de suas atividades para seus afiliados e retendo os lucros financeiros para si próprias.

Essa é a razão pela qual algumas cooperativas centrais apresentam balanços com resultados positivos, enquanto muitas regionais vivem em situação financeira precária. Muitas vezes, estas últimas são obrigadas a procurar recursos em outras atividades, tais como aluguel de carros ou venda de gasolina ${ }^{8}$ : são somente intermediárias no processo de captação de excedentes, repassando-os para as indústrias de derivados, ou seja, as cooperativas centrais.

De outro lado, algumas centrais já assumiram um comportamento de concorrência empresarial frente a suas próprias afiliadas: vendem-lhes insumos a preço de mercado, com lucro, ou chegam a abrir postos de recepção de leite nas áreas de influência de suas cooperativas regionais, quando isso lhes parece mais rentável.

Os conflitos entre centrais e regionais não podem ser vistos, no entanto, fora da situação de dependência mútua em que se encontram. A própria diretoria das centrais é escolhida por representantes de suas cooperativas afiliadas, e estas últimas possuem grande parte do capital das centrais. Muitas vezes, essa participação, compulsoriamente retida, chega até a ultrapassar o capital próprio de que as regionais dispõem para si. De outro lado, as cooperativas regionais precisam da organização centralizada das centrais, no que diz respeito ao transporte e à comercialização de sua produção. Dependem, pois, das centrais, através de vários mecanismos financeiros, econômicos e organizacionais.

\footnotetext{
8 “CADE investiga oito cooperativas de leite", in Jornal do Brasil, 27 de setembro de 1974.
}

Dentro desse quadro, não é de se estranhar que o cooperativismo leiteiro apresente um dos principais problemas do sistema associativo brasileiro em geral, o problema da não participação e da não identificação dos cooperados. Para eles, a cooperativa pode chegar a se assimilar a qualquer empresa comercializadora de leite: a palavra "cooperativa", tal como ela é usada por muitos produtores, serve para indicar a empresa para quem entregam suas matérias-primas, seja uma associação de produtores, seja uma empresa privada de capital nacional ou estrangeiro. Acontece frequentemente ouvir-se falar da Nestlé ou da Danone como de "cooperativas"! E de fato, não pode existir muita diferença, aos olhos dos produtores, entre os dois tipos de empresas: em muitos casos, as duas têm o mesmo comportamento, oferecem as mesmas vantagens etc. $\mathrm{Na}$ área leiteira, especialmente, é difícil falar em retorno financeiro aos cooperados, por causa da baixa rentabilidade do produto.

A necessidade de se adaptar às exigências de um mercado liderado por corporações de capital altamente concentrado e a consequente escolha, pelas cooperativas centrais, de um esquema fortemente empresarial, entra em choque com a difusão da ideologia cooperativista entre seus associados: se o fortalecimento do sistema de cooperativas se faz por sua transformação em empresas capitalistas cada vez mais concentradas, isso dificultará, necessariamente, a identificação do produtor com sua cooperativa e sua consequente participação associativa.

O controle do poder político, dentro das cooperativas locais, depende das diferentes características regionais e sociais: em algumas regiões leiteiras, a representação dos produtores é homogênea; em outras, os conflitos políticos dentro das cooperativas refletem a diversidade de suas condições de produção e de vida. Esses elementos devem ser levados em conta quando se tenta entender a situação de cada cooperativa específica.

Quais são, agora, as relações existentes entre as cooperativas regionais, tão diversas em vários aspectos, e as grandes empresas de laticínios de capital privado nacional ou estrangeiro?

Voltando ao exemplo da Nestlé, vemos que essas relações são complexas: em certos casos, são relações de concorrência para obtenção do leite cru; em outros, as cooperativas foram totalmente subordinadas à empresa. 
O fenômeno de subordinação das cooperativas às empresas privadas se desenvolveu particularmente na área do leite: muitas cooperativas leiteiras regionais se tornaram simples intermediárias entre a Nestlé, por exemplo, e seus produtores. $\mathrm{O}$ caso mais frequente é o das cooperativas que se encarregam do transporte do leite, recolhendo os frascos nas fazendas e entregando-os na fábrica. Outras vezes, as cooperativas também cuidam da venda de insumos, aconselhadas, nisso, pelo serviço de assistência técnica da empresa.

De um lado, essas cooperativas facilitam, sem dúvida, as relações entre a Nestlé e seus fornecedores, centralizando-as. De outro lado, porém, reforçam seu poder de barganha, em função da grande quantidade de leite de que dispõem. Podem utilizá-lo para conseguir certas vantagens por parte da empresa, mas essas pressões, pelo menos nas regiões de implantação antiga, onde a empresa não está mais interessada em expandir-se, ainda parecem surtir efeitos reduzidos.

Em certos casos, a subordinação das cooperativas à empresa é quase total. Na cidade de Três Corações, por exemplo, caso que analisaremos mais detalhadamente na parte a seguir, a cooperativa, cujos diretores têm uma estreita ligação com a Nestlé, tornou-se quase um departamento desta, fazendo serviços que mais nada têm a ver com sua função original. A cooperativa da cidade acabou servindo de departamento de contabilidade para a empresa: esta dá um cheque global para a cooperativa, que é encarregada de distribuir os pagamentos mensais a cada um dos produtores. Sua função quase que se limita a essa atividade.

Frente a essa evolução de um número crescente de cooperativas como órgãos subalternos das transnacionais, defrontam-se concepções contraditórias. A posição do Banco Nacional de Crédito às Cooperativas (BNCC) tenta frear esse fenômeno, não concedendo créditos às cooperativas subordinadas a empresas privadas; na área de laticínios, por outro lado, a Confederação Brasileira de Cooperativas Leiteiras considera isso como estimulante e "inteiramente normal num sistema onde as cooperativas têm a liberdade de fechar contratos com quem quiserem".

\footnotetext{
${ }^{9}$ Entrevista com o Presidente da CBCL, março de 1978.
}

\subsection{A empresa em Três Corações}

Para entender melhor a atuação da Nestlé em suas áreas de implantação, foi realizado um estudo de caso.

A primeira fábrica da empresa em Minas Gerais foi implantada em 1957, em Três Corações, pequena cidade de certa importância no Sul do Estado e conhecido centro de comercialização de gado. Nessa época, a região vivia basicamente de atividades agropecuárias, com destaque para a produção de café, leite e policultura alimentar. A cidade, estrategicamente localizada entre São Paulo, Rio de Janeiro e Belo Horizonte, já dispunha de vias de comunicação com esses centros consumidores e apresentava condições de clima e solo, muito favoráveis à expansão da pecuária leiteira existente.

Em 1958, um ano depois de sua implantação, a fábrica recebeu $6.300 \mathrm{t}$ de leite, de fornecedores localizados numa área de $985 \mathrm{~km}^{2}$. Em 1978, 20 anos mais tarde, a Nestlé de Três Corações dispunha de uma capacidade instalada de 360 mil litros por dia, e recebia leite de 1.589 produtores individuais e de um número ligeiramente maior de associados a quatro cooperativas regionais. ${ }^{10}$

Em sua área de recebimento, que abrange 36 municípios, não é a única compradora: convive com pequenas fábricas de queijo, algumas cooperativas regionais e dois laticínios de porte médio. No entanto, controla a parte mais importante da produção de leite $\mathrm{C}$ na região e nenhuma de suas concorrentes chega a ameaçá-la seriamente. ${ }^{11}$

\footnotetext{
${ }^{10}$ Alpinópolis, Lavras, Três Pontas e São Tiago.

${ }^{11}$ Esses municípios pertencem às microrregiões homogêneas $\mathrm{n}^{\circ} 191$ (quase inteira), 195 (parte oeste), 199 (parte noroeste), 198 (parte nordeste) e 190 (parte leste). Trata-se de Aguanil, Alpinópolis, Bom Sucesso, Camacho, Cambuquira, Campo Belo, Cana Verde, Candeias, Carmo da Cachoeira, Carme da Mata, Carmópolis de Minas, Coqueiral, Cristais, Ibituruna, ljaci, Ingaí, Itapecerica, Itumirim, Itutinga, Lambari, Lavras, Luminárias, Nepomuceno, Oliveira, Passa-Tempo, Perdões, Ribeirão Vermelho, Santana da Vargem, Santana do Jacaré, Santo Antônio do Amparo, São Bento Abade, São Francisco de Oliveira, São João Del Rei, São Tiago, São Tomé das Letras, Três Corações e Três Pontas. Suas maiores concorrentes locais são a Figuinha, em Oliveira, a Cacisa, em Campo Belo, e as Cooperativas de Lavras, Carmo da Cachoeira e Carmópolis. Sua área de atuação é delimitada pela presença da Anderson-Clayton a leste; da Vigor, a sudeste; da Vigor e da Danone, a sudoeste: da Parmalat, ao sul; e da Nestlé/Calciolandia, a noroeste.
} 
No que diz respeito às unidades produtivas, pode-se dizer, de um modo geral, que, nos estabelecimentos menores, a produção é dirigida principalmente para o autoconsumo, gerando pequenos excedentes comercializáveis, enquanto os estabelecimentos médios e grandes se dirigem prioritariamente ao mercado. A pecuária leiteira é uma atividade comum a todos os tamanhos de unidades agropecuárias, seja sob a forma de excedentes, seja sob a de mercadoria capitalista. Os produtores, no entanto, não se dedicam unicamente a esse tipo de produção: somente em alguns municípios da parte leste da área de recebimento, ela é uma atividade quase exclusiva. No restante, muitos produtores têm um rebanho misto (para leite e carne) e se dedicam, também, a amplas atividades agrícolas.

Em 1950, a produção de leite era pouco diferenciada: havia poucas diferenças de produtividade entre os vários municípios, sendo que os que apresentavam características ligeiramente mais avançadas encontravam-se espalhados por toda a área. Quando comparamos esses dados com os do Censo Agropecuário de 1970, destacam-se duas observações: primeiramente, os índices de maior produtividade, anteriormente mais espalhados, concentraram-se nos municípios centrais da área de recebimento da Nestlé, formando um eixo norte-sul que passa por Três Corações, Lavras e Santo Antônio do Amparo. Esse eixo, que corresponde ao centro de sua região de atuação, desenvolveu-se ao longo da principal estrada rodoviária que liga Belo Horizonte a São Paulo.

A segunda constatação concerne aos municípios de Três Corações e de seu posto de recebimento mais próximo, Lavras. Os dois, que apresentavam uma produtividade média em 1950, tornaram-se dois entre os quatro municípios com maior produtividade da região em 1970 (com 2,8 litros por dia e por vaca). Três Corações, mais particularmente, tornou-se o primeiro município produtor de leite do Sul de Minas, com uma produção de 18.865 mil litros em 1970.

Esses dados fornecem a indicação de que a empresa desempenhou, sem dúvida, um papel importante na melhoria da produção e da produtividade leiteira da região, particularmente nas áreas mais próximas aos seus postos de recebimento: favoreceu claramente a modernização das técnicas de produção, embora, como acabamos de ver, esse incentivo tenha sido dirigido prioritariamente a um número reduzido de fazendas. Não parece, no entanto, ter provocado o fim de outros cultivos. Numa primeira fase, pode ter relegado a um segundo plano de prioridades a produção de bens alimentícios de base, mas nunca isso chegou a significar um processo substitutivo, em decorrência da baixa rentabilidade do leite. Quando incentivou a expansão da pecuária leiteira da região, foi em pastagens naturais ou em áreas abandonadas pela produção cafeeira. ${ }^{12}$

Segundo pesquisa da empresa, a maior parte das propriedades de seus fornecedores é constituída de pastagens $( \pm 80 \%)$, qualquer que seja :o estrato a que pertençam. ${ }^{13}$ Essa constatação, no entanto, não define tais propriedades como tendo na pecuária sua principal atividade, porque, muitas vezes, as pastagens são terras cansadas ou acidentadas, que dificilmente poderiam servir para cultivo. Quanto à composição do rebanho, como se trata de uma bacia leiteira bastante antiga, já houve tempo suficiente para cruzamento com reprodutores leiteiros europeus e ele se constitui principalmente de gado cruzado (europeu-zebu).

As técnicas de produção leiteira utilizadas pelos fornecedores da Nestlé dependem, evidentemente, de sua capacidade de capitalização, que difere muito, segundo se trate de produção de excedentes ou de produção mercantil. Outro aspecto que deve ser considerado é o regional: na parte oeste, tradicionalmente uma área de produção de café e onde essa atividade foi intensificada, durante a última década, por um programa de incentivos oficiais, à modernização cafeeira se seguiu uma modernização das técnicas de produção leiteira: graças à sua maior rentabilidade, a cafeicultura tem condições de pagar salários mais altos à numerosa mão-de-obra que absorve e provoca uma diminuição da força de trabalho disponível para o setor leiteiro. Estimulou, assim, uma racionalização das técnicas produtivas deste último. Nas regiões não-cafeeiras, a baixa rentabilidade da produção leiteira tradicional freou o processo de modernização da última década.

\footnotetext{
${ }^{12}$ Isso é evidenciado no Censo: em 1950, 75\% da área foram classificados como "pastagen naturais e artificiais" e, em 1970, essa proporção tinha aumentado para 80\%, em prejuízo, principalmente, das terras não-utilizadas; as áreas de lavouras temporárias subiram, nesse intervalo, de $6,8 \%$ para $8,2 \%$.

13 Assistência Nestlé aos Produtores de Leite, 1973. Os dados provavelmente são superestimados, em virtude da forte proporção de grandes produtores na amostragem, e também porque certos pequenos produtores se agrupam para entregar seu leite, sendo levantados como um só produtor.
} 
$\mathrm{Na}$ área de recebimento como um todo, os estabelecimentos maiores alcançaram um nível de modernização muito alto: como se trata de uma área tradicionalmente leiteira, chegaram, ao longo dos anos, a uma infraestrutura bastante desenvolvida. Quanto a explorações menores, fizeram menos investimentos em instalações fixas e maquinaria agrícola, graças à sua menor capacidade de capitalização e ao caráter pouco compensador do preço do leite.

\subsection{Os fornecedores da fábrica de Três Corações ${ }^{14}$}

Uma primeira pergunta que se pode fazer é por que esses produtores preferem vender seu leite para o grupo transnacional e não para uma de suas pequenas concorrentes locais ou regionais.

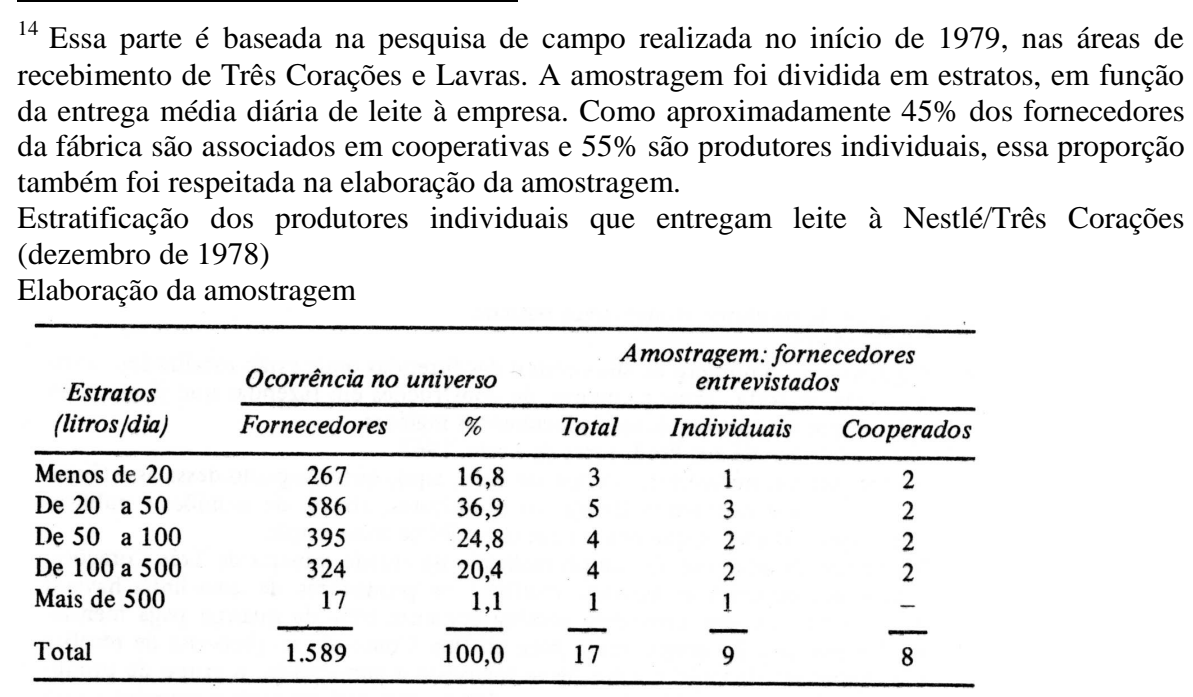

As entrevistas com os fornecedores se dividem em duas partes: a primeira, com o objetivo de caracterizar os produtores, corrobora, em grandes traços, o que foi descrito até agora; a segunda parte, que trata de sua situação atual como produtores de leite, de seus planos futuros e de sua relação com a empresa, será desenvolvida a seguir. Essas entrevistas com os fornecedores da Nestlé foram completadas por outras, com representantes de cooperativas, pequenos laticínios da região, técnicos de órgãos de assistência oficial, outros produtores de leite $\mathrm{C}$ e $\mathrm{B}$, e representantes locais da empresa.
Já vimos que a localização das linhas de leite é essencial e nem sempre muito dinâmica. A isso se soma o fato de que, geralmente, um produtor tem interesse em entregar seu leite, na safra, para o comprador com quem formou sua quota durante a entressafra. ${ }^{15}$ Esses dois aspectos dificultam, sem dúvida, a passagem dos produtores para uma nova empresa compradora.

O que mais motiva os produtores na escolha da empresa para a qual entregarão sua produção é, sem dúvida, o preço oferecido para o produto. O preço mínimo é tabelado, mas certas empresas podem preferir pagar alguns centavos a mais por litro, para garantir a manutenção do seu fornecimento: é o que acontece, frequentemente, quando uma empresa de porte maior se implanta numa região onde existe certa concorrência. Outro motivo importante é o da localização das fazendas em relação às usinas de beneficiamento: como o produtor é responsável pelo transporte do leite de sua fazenda até o posto de recepção e deste último até a usina, ele procurará entregar seu leite à usina mais próxima. Outra razão que os produtores gostam de citar, para explicar sua ligação a uma firma específica, é a garantia (relativa) que esta lhes dá para a compra de todo o leite produzido, durante todo o ano, graças à sua maior capacidade instalada.

A Nestlé apresenta mais um atrativo de peso para os produtores de leite da região: apesar de não pagar hoje um preço maior para o leite que o de concorrentes, é considerada urna empresa muito correta ("as outras prometem muito, mas não cumprem suas promessas"). Ela dispõe de capital de giro bem mais volumoso, e paga o leite recebido sempre em dia, sem atraso nem protesto, e ao preço combinado. As firmas menores, que lutam atualmente com sérias dificuldades financeiras, não oferecem a mesma vantagem para seus fornecedores.

Qual é a situação atual dos produtores da Nestlé na região?

\footnotetext{
${ }^{15}$ Ver a nota ${ }^{\circ} 11$ da Introdução (p.174).
} 


\section{Quadro 7}

\section{Estrutura de produção dos}

fornecedores individuais da Nestlé em Três Corações (1975-1978)

\begin{tabular}{|c|c|c|c|c|c|}
\hline \multirow[b]{2}{*}{ Produção diária } & \multicolumn{2}{|c|}{ Janeiro de 1975} & \multicolumn{2}{|c|}{ Dezembro de 1:978 } & \multirow[b]{2}{*}{$\begin{array}{c}\text { Diferença } \\
\text { entre }(a) \text { e (b) }\end{array}$} \\
\hline & $\begin{array}{c}\text { Número de } \\
\text { produtores (a) }\end{array}$ & $\%$ & $\begin{array}{c}\text { Número de } \\
\text { produtores (b) }\end{array}$ & $\%$ & \\
\hline Menos de 20 litros & 344 & 19,2 & 267 & 16,8 & -77 \\
\hline 20 a 50 litros & 667 & 38,6 & 586 & 36,9 & -81 \\
\hline 50 a 100 litros & 393 & 22,7 & 395 & 24,8 & +2 \\
\hline 100 a 500 litros & 303 & 17,5 & 324 & 20,4 & +21 \\
\hline Mais de 500 litros & 21 & 1,2 & 17 & 1,1 & -4 \\
\hline Total & 1.728 & 100,0 & 1.589 & 100,0 & -139 \\
\hline
\end{tabular}

Fonte: Elaboração da autora, a partir de dados fornecidos pela empresa.

A proporção observada entre o número de produtores e sua entrega diária de leite corresponde, aproximadamente, à estrutura fundiária da região: $70 \%$ dos estabelecimentos levantados pelo Censo de 1970 ocupam uma área de menos de 50ha (ou seja, 20\% da área total). De outro lado, a $16 \%$ dos estabelecimentos correspondem áreas de mais de 100ha (ou seja, $63 \%$ da área total).

Constatou-se, a partir de 1970, um reforço do processo de concentração fundiária, pela diminuição dos pequenos e médios estabelecimentos. $\mathrm{O}$ número total de estabelecimentos agropecuários na região também diminuiu de 21.777, em 1970, para 20.050, em 1975, apesar da incorporação de novas terras.

Isso foi provocado por um forte processo de valorização das terras. Esse processo ocorreu, principalmente, devido à expansão de cultivos modernos, destinados ao abastecimento das capitais, e também devido à implantação de um parque industrial em algumas cidades. Tal processo se nota principalmente na parte sul da região estudada, mais próxima ao Estado de São Paulo, e em volta de cidades que apresentam certo desenvolvimento industrial.

Voltemos ao Quadro 7: ele retrata a evolução da estratificação dos produtores, de janeiro de 1975 até dezembro de 1978: nesses três anos, 139 produtores abandonaram a empresa. As desistências se deram principalmente entre os pequenos produtores e não foram compensadas pelos ligeiros aumentos entre médios e grandes. Quanto à diminuição dos que entregam mais de 500 litros diários, é devida, provavelmente, à sua mudança para produção de leite B. As desistências foram maiores nas áreas de concorrência e não ocorreram com tanta frequência onde a Nestlé é a única recebedora, o que leva a crer que todos esses fornecedores não abandonaram necessariamente a produção leiteira.

A Nestlé não seria capaz de garantir a permanência de seus fornecedores, protegendo-os contra propostas de concorrentes? Parece mais que o grupo transnacional não está recorrendo ao esquema que montou para esse objetivo ("Antes, quando um fazendeiro pensava em largar a companhia, ela mandava técnicos para convencê-lo a ficar. Hoje, estão quase agradecendo ao produtor que quer sair").

$\mathrm{Na}$ época da pesquisa local (1979), todos os produtores da região se queixavam do baixo preço do leite e da sua pequena rentabilidade. Raros eram os que pensavam em continuar, no futuro, com a produção leiteira como principal atividade: somente quatro entre os 17 entrevistados - todos produtores de menos de 50 litros diários, que não tinham outras alternativas - declararam querer continuar produzindo leite nesses termos. Entre os outros pequenos produtores entrevistados, um se estava desfazendo de suas últimas vacas e trabalhando em fazendas vizinhas, um tinha parado recentemente e mudado para a cidade, e os outros estavam plantando café ou vendendo gado, reduzindo a importância de sua produção leiteira.

Entre os produtores maiores, muitos se dedicam à comercialização de gado e consideram a venda de leite uma atividade secundária. Para os fazendeiros que possuem gado comum, mestiço, é fácil passar para a venda de gado de corte, que lhes garante, atualmente, uma renda maior. Para os produtores mais capitalizados, porém, o problema é maior, porque fizeram investimentos, compraram gado leiteiro holandês, e estão ligados a compromissos bancários dos quais dificilmente conseguem livrar-se.

A falta de rentabilidade do leite se evidencia claramente nos investimentos feitos para a melhoria da produção leiteira. Essas melhorias foram pouco numerosas nestes últimos anos, mas, mesmo assim, os produtores compraram implementos agrícolas, reformaram pastos, 
plantaram capineiras, construíram silos etc. Independentemente de terem sido financiadas ou não, essas melhorias foram pagas de alguma forma, e os pagamentos não puderam ser efetuados exclusivamente com a renda de sua produção leiteira. Ao lado da venda de bezerros, comum a todos os estratos de produtores, os pequenos tiveram de completar essa quantia com a venda de excedentes agrícolas ou a venda de sua força de trabalho, e os produtores maiores, com venda de gado, terras, produtos agrícolas ou com recursos alheios à fazenda.

Todos os fornecedores se queixam da falta de rentabilidade do leite, mas eles se queixam, também, dos desestímulos que sofrem por parte da empresa: esta, durante a época da safra de 1978-1979, não aceitou um litro acima da quota que os produtores tinham apresentado durante a entressafra precedente, apesar de trabalhar somente com parte de sua capacidade instalada. Dessa maneira, obrigou seus fornecedores a desmamar as vacas antes da época ou a mandá-las para o abate.

Frente a todos esses desestímulos, frente a uma renda muitas vezes negativa, por que esses fornecedores continuam produzindo leite e entregando-o à empresa?

Como a maioria não contabiliza sua força de trabalho nem sua propriedade como custo, eles continuam sem perdas nem lucros, recebendo uma quantia de dinheiro líquido a cada mês. Esse dinheiro é essencial para pagar as despesas familiares como alimentação, vestuário e saúde, e algumas despesas mensais da exploração agropecuária, como a compra de rações, salários de empregados etc.: a produção leiteira fornece, mensalmente, ao produtor o capital de giro que lhe falta e que não consegue com a venda de suas colheitas agrícolas anuais. A renda do leite não é suficiente para permitir-lhe fazer investimentos, nem mesmo, muitas vezes, para cobrir os custos diários de sua exploração, mas é essencial, porque se trata de dinheiro líquido, com o qual ele pode contar para pagar parte de suas despesas mensais.

Ao produtor faltam alternativas que lhe garantam uma renda imediata e regular desse tipo. A atividade leiteira, mesmo não sendo rentável, é uma atividade segura: a certeza de conseguir vender a produção quase toda e a regularidade do pagamento compensam a fraca rentabilidade constatada.
Para todos os produtores, existe um risco sério em reorientar sua produção. Os grandes, ainda mais, têm capitais importantes imobilizados na exploração leiteira. Quanto aos pequenos, faltam-lhes, muitas vezes, alternativas de emprego, na agricultura ou em outro setor da economia.

O caráter complementar da pecuária leiteira, nesses estabelecimentos, favorece, sem dúvida, a empresa, porque lhe permite uma maior flexibilidade em termos de recepção: uma recusa de leite da sua parte provocará menos conflitos com seus fornecedores que no caso em que estes dependessem exclusivamente desse produto para sua subsistência. No caso que estudamos aqui, a empresa tem facilidade em transferir o risco da comercialização de seus produtos para seus fornecedores, adaptando seu recebimento a suas estratégias de mercado.

\subsection{Tendência migratória da Nestlé no Brasil}

É difícil distinguir o caráter da redução do recebimento da empresa em Três Corações: pode ser uma política passageira ${ }^{16}$ como pode significar, também, um desestímulo profundo à pecuária leiteira regional, se continuada a longo prazo. Esse fenômeno não pode ser devido somente a uma decisão da Nestlé em diminuir sua produção de leite em pó, porque está abrindo novas fábricas em outras regiões. Pode estar ligado, no entanto, a uma tendência constante no comportamento do grupo suíço, verificada tanto no Brasil quanto em outros países da América Latina ${ }^{17}$ : a tendência em se afastar cada vez mais dos núcleos industriais, criando novos centros mais dinâmicos para a produção de leite.

Nas regiões tradicionais, o setor leiteiro não consegue mais se expandir de maneira satisfatória para a empresa. Isso se deve, principalmente, ao caráter extensivo dessa atividade: a distância existente entre a elevação do preço da terra e o rendimento da pecuária leiteira ao produtor não permite maior expansão da produção. A empresa procura,

16 A empresa costuma recorrer a mecanismos de pressão para aumentar o preço de seu produto acabado no mercado consumidor. Manobras desse tipo são possíveis, graças à sua vantajosa posição no mercado de leite em pó (ver, por exemplo, "Produtores dizem que leite em pó integral vai sumir do mercado", in Folha de São Paulo, 29 de abril de 1977).

${ }^{17}$ Nestlé S.A., 1975. Essa tendência foi verificada em todos os países de pecuária extensiva e com condições de criar novos pólos de expansão leiteira. 
pois, regiões mais afastadas dos grandes centros urbanos, onde o preço da terra é mais barato e onde ela pode controlar a produção leiteira em condições de monopsônio absoluto: foge, assim, aos altos custos de produção, à concorrência na procura de sua matéria-prima e às acusações de diminuir o abastecimento de leite fluido nas capitais. É mais lucrativo, para a empresa, implantar uma fábrica em nova região do que lutar contra fatores estruturais que impeçam a expansão do setor leiteiro tradicional. Essa diminuição dos estímulos da Nestlé à pecuária de determinada região é facilitada pelo fato de que os produtores já criaram alguns mecanismos para absorver os riscos da comercialização leiteira.

Nessa tendência para a expansão territorial em áreas potenciais ainda pouco exploradas, a empresa contou, no Brasil, com a colaboração das políticas de incentivos fiscais regionais da Sudam, na Região Amazônica, e da Sudene, no Nordeste. Esses incentivos à desconcentração industrial vieram ao encontro de sua necessidade de expansão territorial, que surge em todo país em que a empresa esteja implantada há várias décadas, perto de centros urbanos de alto crescimento.

O estudo da situação em Três Corações, caso de implantação antiga da Nestlé, onde o leite já não é mais um produto dinâmico, poderia ser completado por uma pesquisa de campo numa região de instalação recente. Assim, poder-se-ia comparar a atuação da empresa em dois lugares: um, de expansão da produção leiteira, e outro, de quase-estagnação. Note-se que a atuação do grupo suíço na região estudada foi importante principalmente em sua época de implantação, quando teve de organizar e disciplinar seu mercado fornecedor. Depois, uma vez assegurado seu fornecimento, seu papel na região se tornou mais conservador. Por essa razão, seria interessante estudar, também, o caso de uma região de implantação recente da empresa. 